\title{
Fixed point theorems for mappings satisfying contractive conditions of integral type
}

Zeqing Liu', Yan Lu' and Shin Min Kang ${ }^{2 *}$

\section{*Correspondence:}

smkang@gnu.ac.kr

2Department of Mathematics and

RINS, Gyeongsang National

University, Jinju, 660-701, Korea

Full list of author information is

available at the end of the article

\begin{abstract}
Two results involving the existence, uniqueness and iterative approximations of fixed points for two contractive mappings of integral type are proved in complete metric spaces. Two nontrivial examples are included.

MSC: $54 \mathrm{H} 25$
\end{abstract}

Keywords: contractive mappings of integral type; fixed point; complete metric space

\section{Introduction}

In recent years, there has been increasing interest in the study of fixed points and common fixed points of mappings satisfying contractive conditions of integral type, see, for example, [1-14] and the references cited therein. Branciari [4] introduced first the contractive mapping of integral type as follows:

$$
\int_{0}^{d(f x, f y)} \varphi(t) d t \leq c \int_{0}^{d(x, y)} \varphi(t) d t, \quad \forall x, y \in X,
$$

where $c \in(0,1)$ is a constant, $\varphi \in \Phi=\left\{\varphi: \varphi: \mathbb{R}^{+} \rightarrow \mathbb{R}^{+}\right.$satisfies that $\varphi$ is Lebesgue integrable, summable on each compact subset of $\mathbb{R}^{+}$and $\int_{0}^{\varepsilon} \varphi(t) d t>0$ for each $\left.\varepsilon>0\right\}$ and proved the existence of a fixed point for the mapping in complete metric spaces. Rhoades [10] and Liu et al. [8] extended Branciari's result and obtained a few fixed point theorems for the contractive mappings of integral type below:

$$
\int_{0}^{d(f x, f y)} \varphi(t) d t \leq c \int_{0}^{M(x, y)} \varphi(t) d t, \quad \forall x, y \in X
$$

and

$$
\int_{0}^{d(f x, f y)} \varphi(t) d t \leq \alpha(d(x, y)) \int_{0}^{d(x, y)} \varphi(t) d t, \quad \forall x, y \in X
$$

where $c \in(0,1)$ is a constant, $\varphi \in \Phi$ and $\alpha: \mathbb{R}^{+} \rightarrow[0,1)$ is a function with $\lim _{\sup } \operatorname{su}_{s \rightarrow t} \alpha(s)<$ $1, \forall t>0$. Mongkolkeha and Kumam [9] proved fixed point and common fixed point theorems for $\rho$-compatible mapping satisfying a generalized weak contraction of integral type in modular spaces. Sintunavarat and Kumam $[11,12]$ gave common fixed point theorems 
for single-valued and multi-valued mappings satisfying strict general contractive conditions of integral type.

Inspired and motivated by the results in [1-14], in this paper, we introduce two new classes of contractive mappings of integral type in complete metric spaces and study the existence, uniqueness and iterative approximations of fixed points for the mappings. The results obtained in this paper generalize and improve Theorem 2.1 in [4], Theorem 3.1 in [8] and Theorem 2 in [10]. Two nontrivial examples are constructed.

\section{Preliminaries}

Throughout this paper, we assume that $\mathbb{R}=(-\infty,+\infty), \mathbb{R}^{+}=[0,+\infty), \mathbb{N}$ denotes the set of all positive integers, $\mathbb{N}_{0}=\{0\} \cup \mathbb{N}$,

$\Phi_{1}=\left\{\phi: \phi: \mathbb{R}^{+} \rightarrow \mathbb{R}^{+}\right.$is upper semi-continuous on $\mathbb{R}^{+} \backslash\{0\}, \phi(0)=0$ and $\phi(t)<t$, $\forall t>0\}$;

$\Phi_{2}=\left\{\phi: \phi: \mathbb{R}^{+} \rightarrow \mathbb{R}^{+}\right.$is right upper semi-continuous on $\mathbb{R}^{+} \backslash\{0\}, \phi(0)=0$ and $\phi(t)<t$, $\forall t>0\}$;

$\Phi_{3}=\left\{\phi: \phi: \mathbb{R}^{+} \rightarrow \mathbb{R}^{+}\right.$is continuous, $\phi(0)=0, \phi(t)>0, \forall t>0$ and $\lim _{n \rightarrow \infty} t_{n}=0$, for each sequence $\left\{t_{n}\right\}_{n \in \mathbb{N}} \subset \mathbb{R}^{+}$with $\left.\lim _{n \rightarrow \infty} \phi\left(t_{n}\right)=0\right\}$;

$\Phi_{4}=\left\{\phi: \phi: \mathbb{R}^{+} \rightarrow \mathbb{R}^{+}\right.$is strictly increasing, $\phi(0)=0$, continuous at 0 and $\lim _{n \rightarrow \infty} t_{n}=0$ for each sequence $\left\{t_{n}\right\}_{n \in \mathbb{N}}$ in $\mathbb{R}^{+}$with $\left.\lim _{n \rightarrow \infty} \phi\left(t_{n}\right)=0\right\}$;

$\Phi_{5}=\left\{\phi: \phi\right.$ is in $\Phi_{4}$ and is left continuous on $\left.\mathbb{R}^{+} \backslash\{0\}\right\}$;

(a1) $(\varphi, \phi, \psi) \in \Phi \times \Phi_{1} \times \Phi_{3}$;

(a2) $(\varphi, \phi, \psi) \in \Phi \times \Phi_{2} \times \Phi_{4}$;

(a3) $(\varphi, \phi, \psi) \in \Phi \times \Phi_{2} \times \Phi_{5}$.

Let $T$ be a mapping from a metric space $(X, d)$ into itself, and let $\psi: \mathbb{R}^{+} \rightarrow \mathbb{R}^{+}$be a function. Put

$$
M(x, y)=\max \left\{d(x, y), d(x, T x), d(y, T y), \frac{1}{2}[d(x, T y)+d(y, T x)]\right\}, \quad \forall x, y \in X,
$$

$\psi(s+)$ and $\psi(s-)$ denote the right and left limits of the function $\psi$ at $s \in \mathbb{R}^{+}$, respectively.

The following lemmas play important roles in this paper.

Lemma 2.1 [8] Let $\varphi \in \Phi$ and $\left\{r_{n}\right\}_{n \in \mathbb{N}}$ be a nonnegative sequence with $\lim _{n \rightarrow \infty} r_{n}=a$. Then

$$
\lim _{n \rightarrow \infty} \int_{0}^{r_{n}} \varphi(t) d t=\int_{0}^{a} \varphi(t) d t
$$

Lemma 2.2 [8] Let $\varphi \in \Phi$ and $\left\{r_{n}\right\}_{n \in \mathbb{N}}$ be a nonnegative sequence. Then

$$
\lim _{n \rightarrow \infty} \int_{0}^{r_{n}} \varphi(t) d t=0
$$

if and only if $\lim _{n \rightarrow \infty} r_{n}=0$.

\section{Fixed point theorems and examples}

In this section, we prove two fixed point theorems for two classes of contractive mappings of integral type and display two examples as applications of the theorems. 
Theorem 3.1 Let $(X, d)$ be a complete metric space, and let $T: X \rightarrow X$ be a mapping satisfying

$$
\int_{0}^{\psi(d(T x, T y))} \varphi(t) d t \leq \phi\left(\int_{0}^{\psi(d(x, y))} \varphi(t) d t\right), \quad \forall x, y \in X,
$$

where $\varphi, \phi$ and $\psi$ satisfy (a1) or (a2). Then $T$ has a unique fixed point $a \in X$ and $\lim _{n \rightarrow \infty} T^{n} x_{0}=$ a for each $x_{0} \in X$.

Proof Let $x_{0}$ be an arbitrary point in $X$. Put $x_{n}=T x_{n-1}$ for each $n \in \mathbb{N}$. Assume that $x_{n_{0}}=$ $x_{n_{0}-1}$ for some $n_{0} \in \mathbb{N}$. It is easy to see that $x_{n_{0}-1}$ is a fixed point of $T$, and there is nothing to prove. Assume that $x_{n} \neq x_{n-1}$ for all $n \in \mathbb{N}$. From (3.1) and one of (a1) and (a2), we obtain that

$$
\begin{aligned}
\int_{0}^{\psi\left(d\left(x_{n+1}, x_{n}\right)\right)} \varphi(t) d t & =\int_{0}^{\psi\left(d\left(T x_{n}, T x_{n-1}\right)\right)} \varphi(t) d t \leq \phi\left(\int_{0}^{\psi\left(d\left(x_{n}, x_{n-1}\right)\right)} \varphi(t) d t\right) \\
& <\int_{0}^{\psi\left(d\left(x_{n}, x_{n-1}\right)\right)} \varphi(t) d t, \quad \forall n \in \mathbb{N},
\end{aligned}
$$

which implies that

$$
0<\psi\left(d\left(x_{n+1}, x_{n}\right)\right)<\psi\left(d\left(x_{n}, x_{n-1}\right)\right), \quad \forall n \in \mathbb{N} .
$$

Note that (3.3) yields that the sequence $\left\{\psi\left(d\left(x_{n}, x_{n-1}\right)\right)\right\}_{n \in \mathbb{N}}$ is positive and strictly decreasing. Thus, there exists a constant $c \geq 0$ with

$$
\lim _{n \rightarrow \infty} \psi\left(d\left(x_{n}, x_{n-1}\right)\right)=c .
$$

Suppose that $c>0$. Taking upper limit in (3.2) and using (3.4), Lemma 2.1 and one of (a1) and (a2), we conclude that

$$
\begin{aligned}
\int_{0}^{c} \varphi(t) d t & =\limsup _{n \rightarrow \infty} \int_{0}^{\psi\left(d\left(x_{n+1}, x_{n}\right)\right)} \varphi(t) d t \leq \limsup _{n \rightarrow \infty} \phi\left(\int_{0}^{\psi\left(d\left(x_{n}, x_{n-1}\right)\right)} \varphi(t) d t\right) \\
& \leq \phi\left(\int_{0}^{c} \varphi(t) d t\right)<\int_{0}^{c} \varphi(t) d t,
\end{aligned}
$$

which is absurd, and hence $c=0$, that is,

$$
\lim _{n \rightarrow \infty} \psi\left(d\left(x_{n}, x_{n-1}\right)\right)=0,
$$

which together with one of (a1) and (a2) guarantees that

$$
\lim _{n \rightarrow \infty} d\left(x_{n}, x_{n-1}\right)=0
$$

Now, we show that $\left\{x_{n}\right\}_{n \in \mathbb{N}_{0}}$ is a Cauchy sequence. Suppose that $\left\{x_{n}\right\}_{n \in \mathbb{N}_{0}}$ is not a Cauchy sequence, which means that there is a constant $\varepsilon>0$ such that for each positive integer $k$, there are positive integers $m(k)$ and $n(k)$ with $m(k)>n(k)>k$ satisfying

$$
d\left(x_{m(k)}, x_{n(k)}\right)>\varepsilon \text {. }
$$


For each positive integer $k$, let $m(k)$ denote the least integer exceeding $n(k)$ and satisfying the inequality above. It follows that

$$
d\left(x_{m(k)}, x_{n(k)}\right)>\varepsilon \quad \text { and } \quad d\left(x_{m(k)-1}, x_{n(k)}\right) \leq \varepsilon, \quad \forall k \in \mathbb{N} \text {. }
$$

Note that

$$
\begin{aligned}
\varepsilon & <d\left(x_{m(k)}, x_{n(k)}\right) \leq d\left(x_{m(k)}, x_{m(k)-1}\right)+d\left(x_{m(k)-1}, x_{n(k)-1}\right)+d\left(x_{n(k)-1}, x_{n(k)}\right) \\
& \leq d\left(x_{m(k)}, x_{m(k)-1}\right)+d\left(x_{m(k)-1}, x_{n(k)}\right)+2 d\left(x_{n(k)}, x_{n(k)-1}\right), \quad \forall k \in \mathbb{N} .
\end{aligned}
$$

Letting $k \rightarrow \infty$ in (3.7) and using (3.5) and (3.6), we conclude that

$$
\lim _{k \rightarrow \infty} d\left(x_{m(k)}, x_{n(k)}\right)=\lim _{k \rightarrow \infty} d\left(x_{m(k)-1}, x_{n(k)-1}\right)=\varepsilon .
$$

In view of (3.1), we deduce that

$$
\begin{aligned}
\int_{0}^{\psi\left(d\left(x_{m(k)}, x_{n(k)}\right)\right)} \varphi(t) d t & =\int_{0}^{\psi\left(d\left(T x_{m(k)-1}, T x_{n(k)-1}\right)\right)} \varphi(t) d t \\
& \leq \phi\left(\int_{0}^{\psi\left(d\left(x_{m(k)-1}, x_{n(k)-1}\right)\right)} \varphi(t) d t\right), \quad \forall k \in \mathbb{N} .
\end{aligned}
$$

Assume that (a1) holds. Taking upper limit in (3.9) and using (3.8) and Lemma 2.1, we get that

$$
\begin{aligned}
\int_{0}^{\psi(\varepsilon)} \varphi(t) d t & =\limsup _{k \rightarrow \infty} \int_{0}^{\psi\left(d\left(x_{m(k)}, x_{n(k)}\right)\right)} \varphi(t) d t \\
& \leq \limsup _{k \rightarrow \infty} \phi\left(\int_{0}^{\psi\left(d\left(x_{m(k)-1}, x_{n(k)-1}\right)\right)} \varphi(t) d t\right) \\
& \leq \phi\left(\int_{0}^{\psi(\varepsilon)} \varphi(t) d t\right)<\int_{0}^{\psi(\varepsilon)} \varphi(t) d t
\end{aligned}
$$

which is a contradiction.

Assume that (a2) holds. In view of (3.8), there exists $K \in \mathbb{N}$ satisfying

$$
d\left(x_{m(k)-1}, x_{n(k)-1}\right)>\frac{\varepsilon}{2}, \quad \forall k \geq K
$$

It follows from the inequality above and $\psi \in \Phi_{4}$ that

$$
\psi\left(d\left(x_{m(k)-1}, x_{n(k)-1}\right)\right)>\psi\left(\frac{\varepsilon}{2}\right)>0, \quad \forall k \geq K
$$

which together with (3.9) and $\phi \in \Phi_{2}$ gives that

$$
\begin{aligned}
\int_{0}^{\psi\left(d\left(x_{m(k)}, x_{n(k)}\right)\right)} \varphi(t) d t & \leq \phi\left(\int_{0}^{\psi\left(d\left(x_{m(k)-1}, x_{n(k)-1}\right)\right)} \varphi(t) d t\right) \\
& <\int_{0}^{\psi\left(d\left(x_{m(k)-1}, x_{n(k)-1}\right)\right)} \varphi(t) d t, \quad \forall k \geq K,
\end{aligned}
$$


which ensures that

$$
\psi\left(d\left(x_{m(k)}, x_{n(k)}\right)\right)<\psi\left(d\left(x_{m(k)-1}, x_{n(k)-1}\right)\right), \quad \forall k \geq K
$$

that is,

$$
d\left(x_{m(k)}, x_{n(k)}\right)<d\left(x_{m(k)-1}, x_{n(k)-1}\right), \quad \forall k \geq K,
$$

which together with (3.6) and (3.8) implies that

$$
\lim _{k \rightarrow \infty} d\left(x_{m(k)}, x_{n(k)}\right)=\lim _{k \rightarrow \infty} d\left(x_{m(k)-1}, x_{n(k)-1}\right)=\varepsilon .
$$

Taking upper limit in (3.9) and using Lemma 2.1, (a2) and the equations above, we conclude that

$$
\begin{aligned}
\int_{0}^{\psi(\varepsilon+)} \varphi(t) d t & =\limsup _{k \rightarrow \infty} \int_{0}^{\psi\left(d\left(x_{m(k)}, x_{n(k)}\right)\right)} \varphi(t) d t \\
& \leq \limsup _{k \rightarrow \infty} \phi\left(\int_{0}^{\psi\left(d\left(x_{m(k)-1}, x_{n(k)-1}\right)\right)} \varphi(t) d t\right) \\
& \leq \phi\left(\int_{0}^{\psi(\varepsilon+)} \varphi(t) d t\right)<\int_{0}^{\psi(\varepsilon+)} \varphi(t) d t
\end{aligned}
$$

which is a contradiction.

Thus, $\left\{x_{n}\right\}_{n \in \mathbb{N}_{0}}$ is a Cauchy sequence. Since $(X, d)$ is a complete metric space, there exists a point $a \in X$ such that $\lim _{n \rightarrow \infty} x_{n}=a$. By (3.1), Lemma 2.2 and one of $\psi \in \Phi_{3}$ and $\psi \in \Phi_{4}$, we arrive at

$$
\begin{aligned}
0 & \leq \int_{0}^{\psi\left(d\left(x_{n+1}, T a\right)\right)} \varphi(t) d t \leq \phi\left(\int_{0}^{\psi\left(d\left(x_{n}, a\right)\right)} \varphi(t) d t\right) \\
& \leq \int_{0}^{\psi\left(d\left(x_{n}, a\right)\right)} \varphi(t) d t \rightarrow 0 \quad \text { as } n \rightarrow \infty,
\end{aligned}
$$

that is,

$$
\lim _{n \rightarrow \infty} \int_{0}^{\psi\left(d\left(x_{n+1}, T a\right)\right)} \varphi(t) d t=0
$$

which together with Lemma 2.2 means that

$$
\lim _{n \rightarrow \infty} \psi\left(d\left(x_{n+1}, T a\right)\right)=0 .
$$

Note that (3.10) and one of $\psi \in \Phi_{3}$ and $\psi \in \Phi_{4}$ ensure that $\lim _{n \rightarrow \infty} d\left(x_{n+1}, T a\right)=0$. Consequently, we conclude immediately that

$$
d(a, T a) \leq d\left(a, x_{n+1}\right)+d\left(x_{n+1}, T a\right) \rightarrow 0 \quad \text { as } n \rightarrow \infty,
$$

which gives that $a=T a$. 
Next, we show that $a$ is a unique fixed point $T$ in $X$. Suppose that $T$ has another fixed point $b \in X \backslash\{a\}$. It follows from (3.1) and one of (a1) and (a2) that

$$
\begin{aligned}
0 & <\int_{0}^{\psi(d(a, b))} \varphi(t) d t=\int_{0}^{\psi(d(T a, T b))} \varphi(t) d t \\
& \leq \phi\left(\int_{0}^{\psi(d(a, b))} \varphi(t) d t\right)<\int_{0}^{\psi(d(a, b))} \varphi(t) d t,
\end{aligned}
$$

which is a contradiction. This completes the proof.

Remark 3.2 Theorem 3.1 generalizes Theorem 2.1 in [4] and Theorem 3.1 in [8]. The example below is an application of Theorem 3.1.

Example 3.3 Let $X=[0,1] \cup\{3,5\}$ be endowed with the Euclidean metric $d=|\cdot|$. Define $T: X \rightarrow X$ and $\varphi, \phi, \psi: \mathbb{R}^{+} \rightarrow \mathbb{R}^{+}$by

$$
\begin{gathered}
T x=\left\{\begin{array}{ll}
\frac{x}{2}, & \forall x \in[0,1], \\
0, & x=3, \\
1, & x=5,
\end{array} \quad \varphi(t)= \begin{cases}1, & \forall t \in[0,1], \\
e^{t}, & \forall t \in(1,+\infty),\end{cases} \right. \\
\phi(t)=\left\{\begin{array}{ll}
\frac{2}{3} t, & \forall t \in\left[0, \frac{3}{4}\right], \\
2 t-1, & \forall t \in\left(\frac{3}{4}, 1\right), \\
\frac{t^{2}}{1+t}, & \forall t \in[1,+\infty),
\end{array} \quad \psi(t)= \begin{cases}\frac{1}{2} t, & \forall t \in[0,1], \\
t^{2}, & \forall t \in(1,+\infty) .\end{cases} \right.
\end{gathered}
$$

It is easy to see that (a2) holds. Put $x, y \in X$ with $x<y$. To verify (3.1), we need to consider four possible cases as follows.

Case 1. Let $x, y \in[0,1]$. It follows that

$$
\begin{aligned}
\int_{0}^{\psi(d(T x, T y))} \varphi(t) d t & =\int_{0}^{\psi\left(\frac{1}{2}|x-y|\right)} \varphi(t) d t=\frac{1}{4}|x-y| \leq \frac{1}{3}|x-y| \\
& =\phi\left(\int_{0}^{\frac{1}{2}|x-y|} \varphi(t) d t\right)=\phi\left(\int_{0}^{\psi(d(x, y))} \varphi(t) d t\right) ;
\end{aligned}
$$

Case 2. Let $x \in[0,1]$ and $y=3$. Note that $|y-x| \geq 2$ and $e^{|y-x|^{2}}+1-e>e$. It follows that

$$
\begin{aligned}
\int_{0}^{\psi(d(T x, T y))} \varphi(t) d t & =\int_{0}^{\psi\left(\frac{x}{2}\right)} \varphi(t) d t=\frac{1}{4} x \leq \frac{1}{4}<\frac{\left(e^{|y-x|^{2}}+1-e\right)^{4}}{1+\left(e^{|y-x|^{2}}+1-e\right)^{2}} \\
& =\phi\left(e^{|y-x|^{2}}+1-e\right)=\phi\left(\int_{0}^{1} \varphi(t) d t+\int_{1}^{|y-x|^{2}} \varphi(t) d t\right) \\
& =\phi\left(\int_{0}^{\psi(d(x, y))} \varphi(t) d t\right) ;
\end{aligned}
$$

Case 3. Let $x \in[0,1]$ and $y=5$. Notice that $|y-x| \geq 4$. It follows that

$$
\begin{aligned}
\int_{0}^{\psi(d(T x, T y))} \varphi(t) d t & =\int_{0}^{\psi\left(\left|1-\frac{x}{2}\right|\right)} \varphi(t) d t=\frac{1}{2}-\frac{x}{4} \leq \frac{1}{2} \\
& <\frac{\left(e^{|y-x|^{2}}+1-e\right)^{4}}{1+\left(e^{|y-x|^{2}}+1-e\right)^{2}}=\phi\left(e^{|y-x|^{2}}+1-e\right)
\end{aligned}
$$




$$
\begin{aligned}
& =\phi\left(\int_{0}^{1} \varphi(t) d t+\int_{1}^{|y-x|^{2}} \varphi(t) d t\right) \\
& =\phi\left(\int_{0}^{\psi(d(x, y))} \varphi(t) d t\right) ;
\end{aligned}
$$

Case 4. Let $x=3$ and $y=5$. It follows that

$$
\begin{aligned}
\int_{0}^{\psi(d(T x, T y))} \varphi(t) d t & =\int_{0}^{\psi(1)} \varphi(t) d t=\int_{0}^{\frac{1}{2}} \varphi(t) d t=\frac{1}{2}<\frac{\left(e^{4}+1-e\right)^{2}}{1+e^{4}+1-e} \\
& =\phi\left(e^{4}+1-e\right)=\phi\left(1+\int_{1}^{4} \varphi(t) d t\right) \\
& =\phi\left(\int_{0}^{1} \varphi(t) d t+\int_{1}^{4} \varphi(t) d t\right) \\
& =\phi\left(\int_{0}^{\psi(d(x, y))} \varphi(t) d t\right) .
\end{aligned}
$$

That is, (3.1) holds. Thus, Theorem 3.1 implies that $T$ has a unique fixed point $0 \in X$ and $\lim _{n \rightarrow \infty} T^{n} x_{0}=0$ for each $x_{0} \in X$.

Theorem 3.4 Let $(X, d)$ be a complete metric space, and let $T: X \rightarrow X$ be a mapping satisfying

$$
\int_{0}^{\psi(d(T x, T y))} \varphi(t) d t \leq \phi\left(\int_{0}^{\psi(M(x, y))} \varphi(t) d t\right), \quad \forall x, y \in X
$$

where $\varphi, \phi$ and $\psi$ satisfy (a1) or (a3). Then $T$ has a unique fixed point $a \in X$ and $\lim _{n \rightarrow \infty} T^{n} x_{0}=a$ for each $x_{0} \in X$.

Proof Let $x_{0}$ be an arbitrary point in $X$. Put $x_{n}=T x_{n-1}$ for each $n \in \mathbb{N}$. Assume that $x_{n_{0}}=$ $x_{n_{0}-1}$ for some $n_{0} \in \mathbb{N}$. It is easy to see that $x_{n_{0}-1}$ is a fixed point of $T$, and there is nothing to prove. Assume that $x_{n} \neq x_{n-1}$ for all $n \in \mathbb{N}$. From (3.11) and one of (a1) and (a3), we obtain that

$$
\begin{aligned}
\int_{0}^{\psi\left(d\left(x_{n+1}, x_{n}\right)\right)} \varphi(t) d t & =\int_{0}^{\psi\left(d\left(T x_{n}, T x_{n-1}\right)\right)} \varphi(t) d t \leq \phi\left(\int_{0}^{\psi\left(M\left(x_{n}, x_{n-1}\right)\right)} \varphi(t) d t\right) \\
& <\int_{0}^{\psi\left(M\left(x_{n}, x_{n-1}\right)\right)} \varphi(t) d t, \quad \forall n \in \mathbb{N},
\end{aligned}
$$

where

$$
\begin{aligned}
& M\left(x_{n}, x_{n-1}\right) \\
& \quad=\max \left\{d\left(x_{n}, x_{n-1}\right), d\left(x_{n}, T x_{n}\right), d\left(x_{n-1}, T x_{n-1}\right), \frac{1}{2}\left[d\left(x_{n}, T x_{n-1}\right)+d\left(x_{n-1}, T x_{n}\right)\right]\right\} \\
& \quad=\max \left\{d\left(x_{n}, x_{n-1}\right), d\left(x_{n}, x_{n+1}\right), d\left(x_{n-1}, x_{n}\right), \frac{1}{2}\left[d\left(x_{n}, x_{n}\right)+d\left(x_{n-1}, x_{n+1}\right)\right]\right\} \\
& \quad=\max \left\{d\left(x_{n}, x_{n-1}\right), d\left(x_{n}, x_{n+1}\right)\right\}, \quad \forall n \in \mathbb{N} .
\end{aligned}
$$


Suppose that $d\left(x_{n_{0}}, x_{n_{0}-1}\right) \leq d\left(x_{n_{0}}, x_{n_{0}+1}\right)$ for some $n_{0} \in \mathbb{N}$. It follows from (3.12) and (3.13) that

$$
\int_{0}^{\psi\left(d\left(x_{n_{0}+1}, x_{n_{0}}\right)\right)} \varphi(t) d t<\int_{0}^{\psi\left(M\left(x_{n_{0}}, x_{n_{0}-1}\right)\right)} \varphi(t) d t=\int_{0}^{\psi\left(d\left(x_{n_{0}+1}, x_{n_{0}}\right)\right)} \varphi(t) d t,
$$

which is a contradiction. Consequently, we deduce that

$$
d\left(x_{n}, x_{n+1}\right)<d\left(x_{n}, x_{n-1}\right) \quad \text { and } \quad M\left(x_{n}, x_{n-1}\right)=d\left(x_{n}, x_{n-1}\right), \quad \forall n \in \mathbb{N} .
$$

In view of (3.12), (3.14) and one of (a1) and (a3), we get that

$$
\begin{aligned}
\int_{0}^{\psi\left(d\left(x_{n+1}, x_{n}\right)\right)} \varphi(t) d t & \leq \phi\left(\int_{0}^{\psi\left(M\left(x_{n}, x_{n-1}\right)\right)} \varphi(t) d t\right) \\
& =\phi\left(\int_{0}^{\psi\left(d\left(x_{n}, x_{n-1}\right)\right)} \varphi(t) d t\right) \\
& <\int_{0}^{\psi\left(d\left(x_{n}, x_{n-1}\right)\right)} \varphi(t) d t, \quad \forall n \in \mathbb{N},
\end{aligned}
$$

which implies that

$$
\psi\left(d\left(x_{n+1}, x_{n}\right)\right)<\psi\left(d\left(x_{n}, x_{n-1}\right)\right), \quad \forall n \in \mathbb{N},
$$

which means that there exists a constant $c \geq 0$ with $\lim _{n \rightarrow \infty} \psi\left(d\left(x_{n}, x_{n-1}\right)\right)=c$.

Now we show that $c=0$. Otherwise, $c>0$. Taking upper limit in (3.15) and using Lemma 2.1 and one of (a1) and (a3), we conclude that

$$
\begin{aligned}
\int_{0}^{c} \varphi(t) d t & =\limsup _{n \rightarrow \infty} \int_{0}^{\psi\left(d\left(x_{n+1}, x_{n}\right)\right)} \varphi(t) d t \leq \limsup _{n \rightarrow \infty} \phi\left(\int_{0}^{\psi\left(d\left(x_{n}, x_{n-1}\right)\right)} \varphi(t) d t\right) \\
& \leq \phi\left(\int_{0}^{c} \varphi(t) d t\right)<\int_{0}^{c} \varphi(t) d t,
\end{aligned}
$$

which is impossible. Hence $c=0$, that is,

$$
\lim _{n \rightarrow \infty} \psi\left(d\left(x_{n}, x_{n-1}\right)\right)=0,
$$

which together with one of (a1) and (a3) gives that

$$
\lim _{n \rightarrow \infty} d\left(x_{n}, x_{n-1}\right)=0
$$

Next, we claim that $\left\{x_{n}\right\}_{n \in \mathbb{N}_{0}}$ is a Cauchy sequence. Suppose that $\left\{x_{n}\right\}_{n \in \mathbb{N}_{0}}$ is not a Cauchy sequence, which means that there is a constant $\varepsilon>0$ such that for each positive integer $k$, there are positive integers $m(k)$ and $n(k)$ with $m(k)>n(k)>k$ such that

$$
d\left(x_{m(k)}, x_{n(k)}\right)>\varepsilon .
$$


For each positive integer $k$, let $m(k)$ denote the least integer exceeding $n(k)$ and satisfying the inequality above. Obviously, (3.6)-(3.8) hold. Note that

$$
\begin{aligned}
M\left(x_{m(k)-1}, x_{n(k)-1}\right) & \\
= & \max \left\{d\left(x_{m(k)-1}, x_{n(k)-1}\right), d\left(x_{m(k)-1}, T x_{m(k)-1}\right), d\left(x_{n(k)-1}, T x_{n(k)-1}\right),\right. \\
& \left.\frac{1}{2}\left[d\left(x_{m(k)-1}, T x_{n(k)-1}\right)+d\left(x_{n(k)-1}, T x_{m(k)-1}\right)\right]\right\} \\
= & \max \left\{d\left(x_{m(k)-1}, x_{n(k)-1}\right), d\left(x_{m(k)-1}, x_{m(k)}\right), d\left(x_{n(k)-1}, x_{n(k)}\right),\right. \\
& \left.\frac{1}{2}\left[d\left(x_{m(k)-1}, x_{n(k)}\right)+d\left(x_{n(k)-1}, x_{m(k)}\right)\right]\right\} \\
\leq & \max \left\{d\left(x_{m(k)-1}, x_{n(k)-1}\right), d\left(x_{m(k)-1}, x_{m(k)}\right), d\left(x_{n(k)-1}, x_{n(k)}\right),\right. \\
& \left.\frac{1}{2}\left[d\left(x_{m(k)-1}, x_{n(k)-1}\right)+2 d\left(x_{n(k)-1}, x_{n(k)}\right)+d\left(x_{n(k)}, x_{m(k)}\right)\right]\right\}, \quad \forall k \in \mathbb{N} .
\end{aligned}
$$

Combining (3.8), (3.17) and (3.18), we infer that

$$
\lim _{k \rightarrow \infty} M\left(x_{m(k)-1}, x_{n(k)-1}\right)=\varepsilon .
$$

In light of (3.11), we deduce that

$$
\begin{aligned}
\int_{0}^{\psi\left(d\left(x_{m(k)}, x_{n(k)}\right)\right)} \varphi(t) d t & =\int_{0}^{\psi\left(d\left(T x_{m(k)-1}, T x_{n(k)-1}\right)\right)} \varphi(t) d t \\
& \leq \phi\left(\int_{0}^{\psi\left(M\left(x_{m(k)-1}, x_{n(k)-1}\right)\right)} \varphi(t) d t\right), \quad \forall k \in \mathbb{N} .
\end{aligned}
$$

Assume that (a1) holds. Taking upper limit in (3.20) and using (3.8), (3.19) and Lemma 2.1, we get that

$$
\begin{aligned}
\int_{0}^{\psi(\varepsilon)} \varphi(t) d t & =\limsup _{k \rightarrow \infty} \int_{0}^{\psi\left(d\left(x_{m(k)}, x_{n(k)}\right)\right)} \varphi(t) d t \\
& \leq \limsup _{k \rightarrow \infty} \phi\left(\int_{0}^{\psi\left(M\left(x_{m(k)-1}, x_{n(k)-1}\right)\right)} \varphi(t) d t\right) \\
& \leq \phi\left(\int_{0}^{\psi(\varepsilon)} \varphi(t) d t\right)<\int_{0}^{\psi(\varepsilon)} \varphi(t) d t
\end{aligned}
$$

which is a contradiction.

Assume that (a3) holds. Note that (3.19) implies that there exists $K \in \mathbb{N}$ with

$$
M\left(x_{m(k)-1}, x_{n(k)-1}\right)>\frac{\varepsilon}{2}, \quad \forall k \geq K .
$$

By virtue of (a3) and (3.21), we deduce that

$$
\psi\left(M\left(x_{m(k)-1}, x_{n(k)-1}\right)\right)>\psi\left(\frac{\varepsilon}{2}\right)>0, \quad \forall k \geq K .
$$


In terms of (3.20), (3.22) and (a3), we get that

$$
\begin{aligned}
\int_{0}^{\psi\left(d\left(x_{m(k)}, x_{n(k)}\right)\right)} \varphi(t) d t & \leq \phi\left(\int_{0}^{\psi\left(M\left(x_{m(k)-1}, x_{n(k)-1}\right)\right)} \varphi(t) d t\right) \\
& <\int_{0}^{\psi\left(M\left(x_{m(k)-1}, x_{n(k)-1}\right)\right)} \varphi(t) d t, \quad \forall k \geq K,
\end{aligned}
$$

which yields that

$$
\psi\left(d\left(x_{m(k)}, x_{n(k)}\right)\right)<\psi\left(M\left(x_{m(k)-1}, x_{n(k)-1}\right)\right), \quad \forall k \geq K,
$$

that is,

$$
d\left(x_{m(k)}, x_{n(k)}\right)<M\left(x_{m(k)-1}, x_{n(k)-1}\right), \quad \forall k \geq K,
$$

which together with (3.6), (3.8) and (3.19) implies that

$$
\lim _{k \rightarrow \infty} d\left(x_{m(k)}, x_{n(k)}\right)=\lim _{k \rightarrow \infty} M\left(x_{m(k)-1}, x_{n(k)-1}\right)=\varepsilon .
$$

Taking upper limit in (3.20) and using (3.23), (a3) and Lemma 2.1, we conclude that

$$
\begin{aligned}
\int_{0}^{\psi(\varepsilon+)} \varphi(t) d t & =\limsup _{k \rightarrow \infty} \int_{0}^{\psi\left(d\left(x_{m(k)}, x_{n(k)}\right)\right)} \varphi(t) d t \\
& \leq \limsup _{k \rightarrow \infty} \phi\left(\int_{0}^{\psi\left(M\left(x_{m(k)-1}, x_{n(k)-1}\right)\right)} \varphi(t) d t\right) \\
& \leq \phi\left(\int_{0}^{\psi(\varepsilon+)} \varphi(t) d t\right) \\
& <\int_{0}^{\psi(\varepsilon+)} \varphi(t) d t,
\end{aligned}
$$

which is a contradiction.

Thus, $\left\{x_{n}\right\}_{n \in \mathbb{N}_{0}}$ is a Cauchy sequence. It follows from completeness of $(X, d)$ that there exists a point $a \in X$ with $\lim _{n \rightarrow \infty} x_{n}=a$.

Next, we show that $a$ is a fixed point of $T$ in $X$. Suppose that $a \neq T a$. Notice that

$$
\begin{aligned}
M\left(x_{n}, a\right) & =\max \left\{d\left(x_{n}, a\right), d\left(x_{n}, T x_{n}\right), d(a, T a), \frac{1}{2}\left[d\left(x_{n}, T a\right)+d\left(a, T x_{n}\right)\right]\right\} \\
& =\max \left\{d\left(x_{n}, a\right), d\left(x_{n}, x_{n+1}\right), d(a, T a), \frac{1}{2}\left[d\left(x_{n}, T a\right)+d\left(a, x_{n+1}\right)\right]\right\} \\
& \rightarrow d(a, T a) \quad \text { as } n \rightarrow \infty,
\end{aligned}
$$

which guarantees that there exists $K_{1} \in \mathbb{N}$ satisfying

$$
M\left(x_{n}, a\right)=d(a, T a), \quad \forall n \geq K_{1} .
$$


Let (a1) hold. In light of (3.11), (3.24) and Lemma 2.1, we infer that

$$
\begin{aligned}
\int_{0}^{\psi(d(a, T a))} \varphi(t) d t & =\limsup _{n \rightarrow \infty} \int_{0}^{\psi\left(d\left(x_{n+1}, T a\right)\right)} \varphi(t) d t \\
& =\limsup _{n \rightarrow \infty} \int_{0}^{\psi\left(d\left(T x_{n}, T a\right)\right)} \varphi(t) d t \\
& \leq \limsup _{n \rightarrow \infty} \phi\left(\int_{0}^{\psi\left(M\left(x_{n}, a\right)\right)} \varphi(t) d t\right) \\
& =\phi\left(\int_{0}^{\psi(d(a, T a))} \varphi(t) d t\right)<\int_{0}^{\psi(d(a, T a))} \varphi(t) d t,
\end{aligned}
$$

which is a contradiction.

Let (a3) hold. In view of (3.11) and (3.24), we deduce that

$$
\begin{aligned}
\int_{0}^{\psi\left(d\left(x_{n+1}, T a\right)\right)} \varphi(t) d t & =\int_{0}^{\psi\left(d\left(T x_{n}, T a\right)\right)} \varphi(t) d t \leq \phi\left(\int_{0}^{\psi\left(M\left(x_{n}, a\right)\right)} \varphi(t) d t\right) \\
& =\phi\left(\int_{0}^{\psi(d(a, T a))} \varphi(t) d t\right)<\int_{0}^{\psi(d(a, T a))} \varphi(t) d t, \quad \forall n \geq K_{1},
\end{aligned}
$$

which yields that

$$
\psi\left(d\left(x_{n+1}, T a\right)\right)<\psi(d(a, T a)), \quad \forall n \geq K_{1},
$$

that is,

$$
d\left(x_{n+1}, T a\right)<d(a, T a), \quad \forall n \geq K_{1},
$$

which together with (3.25) and $(\varphi, \phi, \psi) \in \Phi \times \Phi_{2} \times \Phi_{5}$ means that

$$
\begin{aligned}
\int_{0}^{\psi(d(a, T a))} \varphi(t) d t & =\int_{0}^{\psi(d(a, T a)-)} \varphi(t) d t=\limsup _{n \rightarrow \infty} \int_{0}^{\psi\left(d\left(x_{n+1}, T a\right)\right)} \varphi(t) d t \\
& \leq \phi\left(\int_{0}^{\psi(d(a, T a))} \varphi(t) d t\right)<\int_{0}^{\psi(d(a, T a))} \varphi(t) d t,
\end{aligned}
$$

which is a contradiction.

Hence $T$ has a fixed point $a \in X$. Finally, we show that $a$ is a unique fixed point of $T$ in $X$. Suppose that $T$ has another fixed point $b \in X \backslash\{a\}$. It follows from (3.11) and one of (a1) and (a3) that

$$
\begin{aligned}
0 & <\int_{0}^{\psi(d(a, b))} \varphi(t) d t=\int_{0}^{\psi(d(T a, T b))} \varphi(t) d t \\
& \leq \phi\left(\int_{0}^{\psi(d(a, b))} \varphi(t) d t\right)<\int_{0}^{\psi(d(a, b))} \varphi(t) d t,
\end{aligned}
$$

which is a contradiction. This completes the proof.

Remark 3.5 Theorem 3.4 extends Theorem 2 in [10]. The following example is an application of Theorem 3.4. 
Example 3.6 Let $X=[0,1] \cup\{2 n: n \in \mathbb{N}\}$ be endowed with the Euclidean metric $d=|\cdot|$.

Define $T: X \rightarrow X$ and $\varphi, \phi, \psi: \mathbb{R}^{+} \rightarrow \mathbb{R}^{+}$by

$$
\begin{gathered}
T x=\left\{\begin{array}{ll}
\frac{x}{2}, & \forall x \in[0,1], \\
\frac{1}{x}, & \forall x \in\{2 n: n \in \mathbb{N}\},
\end{array} \quad\right. \\
\phi(t)=\left\{\begin{array}{ll}
\frac{t}{2}, & \forall t \in[0,1], \\
\frac{t^{2}}{1+t}, & \forall t \in(1,+\infty),
\end{array} \quad \psi(t)= \begin{cases}\frac{t}{2}, & \forall t \in[0,1], \\
\frac{\sqrt{t}}{2}, & \forall t \in(1,+\infty) .\end{cases} \right.
\end{gathered}
$$

Clearly, (a1) holds, $\phi$ and $\psi$ are strictly increasing in $\mathbb{R}^{+}$. Put $x, y \in X$ with $x<y$. To prove (3.11), we need to consider three possible cases as follows.

Case 1. Let $x, y \in[0,1]$. It follows that

$$
M(x, y)=\max \left\{|x-y|,\left|x-\frac{1}{2} x\right|,\left|y-\frac{1}{2} y\right|, \frac{1}{2}\left(\left|x-\frac{1}{2} y\right|+\left|y-\frac{1}{2} x\right|\right)\right\} \in(0,1]
$$

and

$$
\begin{aligned}
\int_{0}^{\psi(d(T x, T y))} \varphi(t) d t & =\int_{0}^{\psi\left(\frac{1}{2}|x-y|\right)} \varphi(t) d t=\frac{1}{16}(x-y)^{2} \leq \frac{1}{8}(x-y)^{2} \\
& =\phi\left(\frac{1}{4}(x-y)^{2}\right)=\phi\left(\int_{0}^{\psi(d(x, y))} \varphi(t) d t\right) \leq \phi\left(\int_{0}^{\psi(M(x, y))} \varphi(t) d t\right) .
\end{aligned}
$$

Case 2. Let $x, y \in\{2 n: n \in \mathbb{N}\}$. Notice that

$$
M(x, y)=\max \left\{|x-y|,\left|x-\frac{1}{x}\right|,\left|y-\frac{1}{y}\right|, \frac{1}{2}\left(\left|x-\frac{1}{y}\right|+\left|y-\frac{1}{x}\right|\right)\right\}>1 .
$$

Suppose that $M(x, y) \in(1,4]$. It follows that

$$
\begin{aligned}
\int_{0}^{\psi(d(T x, T y))} \varphi(t) d t & =\int_{0}^{\psi\left(\left|\frac{1}{x}-\frac{1}{y}\right|\right)} \varphi(t) d t=\int_{0}^{\frac{1}{2}\left|\frac{1}{x}-\frac{1}{y}\right|} \varphi(t) d t=\frac{1}{4}\left(\frac{1}{x}-\frac{1}{y}\right)^{2} \\
& <\frac{1}{16}<\frac{1}{8} M(x, y)=\phi\left(\frac{1}{4} M(x, y)\right)=\phi\left(\int_{0}^{\frac{1}{2} \sqrt{M(x, y)}} \varphi(t) d t\right) \\
& =\phi\left(\int_{0}^{\psi(M(x, y))} \varphi(t) d t\right) .
\end{aligned}
$$

Suppose that $M(x, y)>4$. It follows that

$$
\begin{aligned}
\int_{0}^{\psi(d(T x, T y))} \varphi(t) d t & =\int_{0}^{\psi\left(\left|\frac{1}{x}-\frac{1}{y}\right|\right)} \varphi(t) d t=\int_{0}^{\frac{1}{2}\left|\frac{1}{x}-\frac{1}{y}\right|} \varphi(t) d t=\frac{1}{4}\left(\frac{1}{x}-\frac{1}{y}\right)^{2} \\
& <\frac{1}{16}<\frac{M^{2}(x, y)}{16+4 M(x, y)}=\frac{\frac{1}{16} M^{2}(x, y)}{1+\frac{1}{4} M(x, y)} \\
& =\phi\left(\frac{1}{4} M(x, y)\right)=\phi\left(\int_{0}^{\frac{1}{2} \sqrt{M(x, y)}} \varphi(t) d t\right) \\
& =\phi\left(\int_{0}^{\psi(M(x, y))} \varphi(t) d t\right) .
\end{aligned}
$$


Case 3. Let $x \in[0,1]$ and $y \in\{2 n: n \in \mathbb{N}\}$. It follows that

$$
M(x, y)=\max \left\{|x-y|,\left|x-\frac{x}{2}\right|,\left|y-\frac{1}{y}\right|, \frac{1}{2}\left(\left|x-\frac{1}{y}\right|+\left|y-\frac{x}{2}\right|\right)\right\} \geq\left|y-\frac{1}{y}\right|>1
$$

and

$$
\begin{aligned}
\int_{0}^{\psi(d(T x, T y))} \varphi(t) d t & =\int_{0}^{\psi\left(\left|\frac{x}{2}-\frac{1}{y}\right|\right)} \varphi(t) d t=\int_{0}^{\frac{1}{2}\left|\frac{x}{2}-\frac{1}{y}\right|} \varphi(t) d t \\
& =\frac{1}{4}\left(\frac{x}{2}-\frac{1}{y}\right)^{2} \leq \frac{1}{16}<\max \left\{\frac{1}{8} M(x, y), \frac{M^{2}(x, y)}{16+4 M(x, y)}\right\} \\
& =\phi\left(\frac{1}{4} M(x, y)\right)=\phi\left(\int_{0}^{\psi(M(x, y))} \varphi(t) d t\right),
\end{aligned}
$$

that is, (3.11) holds. Thus, Theorem 3.4 implies that $T$ has a unique fixed point $0 \in X$ and $\lim _{n \rightarrow \infty} T^{n} x_{0}=0$ for each $x_{0} \in X$.

\section{Competing interests}

The authors declare that they have no competing interests.

Authors' contributions

All authors read and approved the final manuscript.

\section{Author details}

'Department of Mathematics, Liaoning Normal University, Dalian, Liaoning 116029, People's Republic of China.

${ }^{2}$ Department of Mathematics and RINS, Gyeongsang National University, Jinju, 660-701, Korea.

\section{Acknowledgements}

The authors would like to thank the referees for useful comments and suggestions. This research was supported by the Science Research Foundation of Educational Department of Liaoning Province (L2012380).

\section{Received: 19 June 2013 Accepted: 28 August 2013 Published: 07 Nov 2013}

\section{References}

1. Aliouche, A: A common fixed point theorem for weakly compatible mappings in symmetric spaces satisfying a contractive condition of integral type. J. Math. Anal. Appl. 322, 796-802 (2006). doi:10.1016/j.jmaa.2005.09.068

2. Altun, I, Türkoğlu, D, Rhoades, BE: Fixed points of weakly compatible maps satisfying a general contractive of integral type. Fixed Point Theory Appl. 2007, Article ID 17301 (2007). doi:10.1155/2007/17301

3. Beygmohammadi, M, Razani, A: Two fixed-point theorems for mappings satisfying a general contractive condition of integral type in the modular space. Int. J. Math. Math. Sci. 2010, Article ID 317107 (2010). doi:10.1155/2010/317107

4. Branciari, A: A fixed point theorem for mappings satisfying a general contractive condition of integral type. Int. J. Math. Math. Sci. 29, 531-536 (2002). doi:10.1155/S0161171202007524

5. Djoudi, A, Aliouche, A: Common fixed point theorems of Greguš type for weakly compatible mappings satisfying contractive conditions of integral type. J. Math. Anal. Appl. 329, 31-45 (2007). doi:10.1016/j.jmaa.2006.06.037

6. Djoudi, A, Merghadi, F: Common fixed point theorems for maps under a contractive condition of integral type. J. Math. Anal. Appl. 341, 953-960 (2008). doi:10.1016/j.jmaa.2007.10.064

7. Jachymski, J: Remarks on contractive conditions of integral type. Nonlinear Anal. 71, 1073-1081 (2009). doi:10.1016/.na.2008.11.046

8. Liu, Z, Li, X, Kang, SM, Cho, SY: Fixed point theorems for mappings satisfying contractive conditions of integral type and applications. Fixed Point Theory Appl. 2011, 64 (2011). doi:10.1186/1687-1812-2011-64

9. Mongkolkeha, C, Kumam, P: Fixed point and common fixed point theorems for generalized weak contraction mappings of integral type in modular spaces. Int. J. Math. Math. Sci. 2011, Article ID 705943 (2011) doi:10.1155/2011/705943

10. Rhoades, BE: Two fixed point theorems for mappings satisfying a general contractive condition of integral type. Int. J. Math. Math. Sci. 63, 4007-4013 (2003). doi:10.1155/S0161171203208024

11. Sintunavarat, W, Kumam, P: Greguš-type common fixed point theorems for tangential multivalued mappings of integral type in metric spaces. Int. J. Math. Math. Sci. 2011, Article ID 923458 (2011). doi:10.1155/2011/923458

12. Sintunavarat, $W$, Kumam, $P:$ Greguš type fixed points for a tangential multi-valued mappings satisfying contractive conditions of integral type. J. Inequal. Appl. 2011, 3 (2011). doi:10.1186/1029-242X-2011-3

13. Suzuki, T: Meir-Keeler contractions of integral type are still Meir-Keeler contractions. Int. J. Math. Math. Sci. 2007, Article ID 39281 (2007). doi:10.1155/2007/39281

14. Vijayaraju, $P$, Rhoades, BE, Mohanraj, R: A fixed point theorem for a pair of maps satisfying a general contractive condition of integral type. Int. J. Math. Math. Sci. 15, 2359-2364 (2005). doi:10.1155/JJMMS.2005.2359 
10.1186/1687-1812-2013-267

Cite this article as: Liu et al.: Fixed point theorems for mappings satisfying contractive conditions of integral type. Fixed Point Theory and Applications 2013, 2013:267

Submit your manuscript to a SpringerOpen ${ }^{\circ}$ journal and benefit from:

- Convenient online submission

- Rigorous peer review

- Immediate publication on acceptance

- Open access: articles freely available online

- High visibility within the field

- Retaining the copyright to your article

Submit your next manuscript at $\gg$ springeropen.com 